\title{
Ambulatory hysteroscopy and its role in the management of abnormal uterine bleeding
}

\author{
Natalie A M Cooper, ${ }^{1}$ Lynne L L Robinson, ${ }^{2}$ T Justin Clark ${ }^{3}$
}

\begin{abstract}
${ }^{1}$ Academic Clinical Lecturer, Women's Health Research Unit, Queen Mary University of London, Blizard Institute, London, UK

${ }^{2}$ Consultant Obstetrician and Gynaecologist, Birmingham Women's Hospital, Birmingham, UK

${ }^{3}$ Consultant Obstetrician and Gynaecologist, Birmingham Women's Hospital and Honorary Professor, The University of Birmingham, Birmingham, UK
\end{abstract}

\section{Correspondence to} Professor T Justin Clark, Birmingham Women's Hospital and Honorary Professor, The University of Birmingham, Birmingham B15 2TG, UK; justin.clark@bwhct.nhs.uk

Received 5 January 2014 Revised 7 July 2015

Accepted 12 August 2015

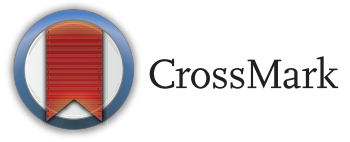

To cite: Cooper NAM Robinson LLL, Clark TJ. J Fam Plann Reprod Health Care 2015:41:284-291.

\begin{abstract}
Hysteroscopy is now an ambulatory procedure, having moved from a conventional day-case operating theatre environment to the outpatient clinic setting. Outpatient hysteroscopy can be used as a diagnostic test and as a therapeutic modality for women presenting with abnormal uterine bleeding. In many cases women can be diagnosed and treated efficiently during a single hospital appointment. This article reviews the development of ambulatory hysteroscopy and how it should optimally be performed and implemented. The contemporary role of this technology for investigating and treating women with abnormal uterine bleeding is then discussed.
\end{abstract}

\section{HYSTEROSCOPY AND THE AMBULATORY SETTING}

Hysteroscopy is defined as the direct endoscopic visualisation of the uterine cavity. It is one of the commonest procedures in contemporary gynaecological practice. Hysteroscopy was originally introduced as an adjunct to 'D\&C' dilatation of the cervix and curettage of the endometrium - to enhance the diagnosis of suspected uterine pathologies, mostly associated with some form of abnormal uterine bleeding (AUB). Improvements in optics and miniaturisation of endoscopes allowed instrumentation of the uterine cavity, under direct vision and without the need for blind dilatation of the cervix. In the light of these developments, the requirement for general anaesthesia has become outdated; pain from insertion of large diameter dilators and endoscopes can be avoided and the enhanced image quality means that investigation can be completed rapidly. Hysteroscopy can also be used to treat uterine disorders associated with

\section{Key message points}

- Hysteroscopy has evolved from a reluctant diagnostic adjunct to traditional 'D\&C' under general anaesthesia in hospital to a predominantly ambulatory procedure.

- Outpatient hysteroscopy allows abnormal uterine bleeding to be treated at the same time as hysteroscopic diagnosis, providing convenience to women and rapid resolution of symptoms.

- Moving services into the outpatient setting has the potential for cost savings and increased efficiency.

AUB. Refinements in ancillary equipment and innovations in technology have allowed small-dimension operative systems to be developed that are suitable for routine use in ambulatory patients.

This review will discuss the rationale, requirements and relevance of ambulatory hysteroscopy in the diagnosis and treatment of AUB, the commonest presenting symptom in gynaecology. A related article on the place and potential of ambulatory hysteroscopy in reproductive health appeared in an earlier issue of this journal, ${ }^{1}$ so matters related to fertility will not be discussed here.

\section{WHAT IS AMBULATORY HYSTEROSCOPY?}

The terms 'outpatient', 'office' and 'ambulatory' are often used interchangeably. Ambulatory hysteroscopy as discussed here refers to an outpatient-based hysteroscopic procedure, performed within adapted hospital or community settings, where the patient remains conscious and walks in and out of the 
department without the need for prolonged postoperative recuperation or monitoring.

Ambulatory hysteroscopy services should aim to:

- Utilise a 'one-stop' 'see and treat' approach

- Avoid multiple patient visits through seamless consultation, testing, treatment and/or planning of clinical management

- Streamline models of care, including provision of appropriately skilled staff and necessary resources and health technologies, avoiding unnecessary bureaucracy and delays

- Implement the latest evidence-based practices in a timely fashion

- Respond to the needs of patients and offer patient choice

- Prioritise the patient experience, especially the management of pain and anxiety

- Reduce hospital admissions (or even attendance at hospital)

- Minimise the need to use expensive operating theatre facilities, but ensure that these remain readily available as part of patient choice.

\section{DEVELOPMENT OF AMBULATORY HYSTEROSCOPY}

Health services worldwide are under significant financial pressures, but the drive to provide medical interventions more efficiently in an ambulatory environment is not simply based on the desire to save money by offering cheaper alternatives. Some of the factors driving the major change from inpatient, hospital-based interventions to ambulatory based ones are listed in Table 1. Provision of more efficient health care is important, but the aspiration of those developing new, innovative ambulatory services is to deliver better medical care compared with current models; care that is more patient-centred, more convenient, safer, more acceptable and more effective (Table 2).

It has been long recognised that inpatient hospital admission can be harmful for patients, with increased risks of complications such as venous thromboembolism and hospital-acquired infection. ${ }^{2-4}$ Furthermore, there are economic disadvantages for individuals, health services and society from prolonged absence from work and use of scarce and expensive hospital resources.
IMPLEMENTING AMBULATORY HYSTEROSCOPY

Close communication between health care professionals from the relevant disciplines, engagement with patients and involvement with clinical managers and health service commissioners are all necessary to implement ambulatory gynaecological services successfully. With regard to hysteroscopy and AUB, a good starting point is to ascertain current activity levels and practices, especially hospital bed use and use of theatre time. A clear vision of what the new ambulatory service aims to deliver should be formulated and projections regarding resources, infrastructure, training, capital and ongoing investments must be made. Forecasted income, cost savings and the need to transfer budgets will have to be considered together with time frames for implementation.

The main obstacle to ambulatory hysteroscopic interventions is procedural feasibility, particularly with regard to ensuring a good patient experience. This primarily concerns adequacy of pain control. An evidence-based guideline covering best practice in outpatient hysteroscopy $(\mathrm{OPH})$ has been published by the Royal College of Obstetricians and Gynaecologists $(\mathrm{RCOG})^{5}$ and is summarised in Box 1. This guidance focuses on diagnostic hysteroscopy, but much of its information is transferable to therapeutic hysteroscopic interventions in the ambulatory setting.

Since publication of the RCOG guidance in 2011 there has been increased interest in optimising patient experience and pain control. Whilst the use of paracervical and intracervical local anaesthesia has been shown in the past to reduce pain in diagnostic hysteroscopy, ${ }^{6}$ the transferability of the findings to modern $\mathrm{OPH}$ is contentious in view of the further miniaturisation of endoscopes, obviating the need for cervical dilatation, and the more widespread adoption of the vaginoscopic technique which avoids the use both of a speculum ${ }^{7}$ and a cervical tenaculum. ${ }^{8}$ There has been recent interest in the use of hysteroscopically-guided injection of local anaesthesia into the uterine body itself prior to outpatient hysteroscopic surgical interventions such as polypectomy and endometrial ablation. ${ }^{9}$ The effectiveness of such approaches requires more evaluation in clinical trials. $^{10}$

Most hospitals now provide ambulatory diagnostic hysteroscopy services and so have the necessary

Table 1 Factors influencing the change from day-case to ambulatory hysteroscopic services

\begin{tabular}{ll}
\hline Influencing factors & Consequences leading to change \\
\hline Minimally invasive diagnosis & Outpatient testing with pelvic ultrasound and endometrial sampling \\
Emphasis on conservative surgery & Alternatives to more invasive, morbid procedures such as hysterectomy, requiring hospital admission \\
Technological advances & Endoscopic imaging; miniaturisation, digitalisation and portability of equipment \\
Benefits for patients and health services & See Table 2 \\
Economic and political considerations & Scarcity of health care resources and capacity. Publications from the DH and the RCOG support local and \\
& community delivery of services ${ }^{47} 4$ \\
\hline
\end{tabular}

DH, Department of Health; RCOG, Royal College of Obstetricians and Gynaecologists. 
Table 2 Relative merits and disadvantages of ambulatory compared with day-case hysteroscopic interventions

\begin{tabular}{|c|c|c|}
\hline Domain & Ambulatory & Day-case* \\
\hline $\begin{array}{l}\text { Pre-operative } \\
\text { work up }\end{array}$ & $\begin{array}{l}\text { Minimal } \\
\text { No need to fast }\end{array}$ & $\begin{array}{l}\text { Pre-operative medical assessment required } \\
\text { - Fasting required }\end{array}$ \\
\hline $\begin{array}{l}\text { Patient-centred } \\
\text { care }\end{array}$ & $\begin{array}{l}\text { Convenient - rapid recovery } \\
\text { Immediacy - verbal communication of diagnosis and } \\
\text { opportunity for simultaneous treatment }\end{array}$ & - Choice of general anaesthesia to avoid peri-operative pain \\
\hline Feasibility & $\begin{array}{l}\text { Procedures possible in women with significant medical } \\
\text { co-morbidities precluding general anaesthesia }\end{array}$ & - Removes limitation of patient tolerability \\
\hline Recovery & $\begin{array}{l}\text { Rapid recovery and discharge } \\
\text { Availability of reclining chairs/hospital trolleys for a } \\
\text { minority of cases }\end{array}$ & $\begin{array}{l}\text { Typical postoperative stays }>4 \text { hours } \\
\text { Postoperative nausea and time to recover from anaesthesia } \\
\text { - Increased likelihood of overnight stay }\end{array}$ \\
\hline Postoperative care & - Minimal - contact phone numbers, regular analgesia & - Requirement to have someone at home overnight \\
\hline Safety & $\begin{array}{l}\text { Self-limiting vasovagal episodes common } \\
\text { - Major peri- or postoperative complications rare }\end{array}$ & $\begin{array}{l}\text { - Additional risks of anaesthesia and surgical trauma in an } \\
\text { anaesthetised patient }\end{array}$ \\
\hline Clinical outcomes & $\begin{array}{l}\text { RCTs required. Data to date support comparable } \\
\text { feasibility, and equivalent effectiveness } \\
\text { Selected procedures appear to be associated with } \\
\text { acceptable patient experience and enhanced safety }\end{array}$ & $\begin{array}{l}\text { Reference standard to compare against. Most procedures feasible } \\
\text { in an ambulatory setting are generally safe, feasible and effective } \\
\text { as a day-case procedure } \\
\text { - Major complications, whilst rare, appear to be more likely }\end{array}$ \\
\hline $\begin{array}{l}\text { Economic } \\
\text { outcomes }\end{array}$ & $\begin{array}{l}\text { Selected procedures appear to be associated with } \\
\text { increased cost-effectiveness }\end{array}$ & - Inferior from an health economics perspective \\
\hline
\end{tabular}

${ }^{*}$ In hospital setting with general or regional anaesthesia.

$\mathrm{RCT}$, randomised controlled trial.

infrastructure in place so that the extra costs needed to implement therapeutic hysteroscopic interventions can be reduced. Additional training will be required, but familiarity with diagnostic OPH and the relative simplicity of the operative procedures, combined with advances in available health technologies, should translate into minimal costs and delays in establishing therapeutic services. Training courses are available for use of the new devices using increasingly sophisticated, realistic and valid simulators. ${ }^{11} 12$

\section{THE ROLE OF AMBULATORY HYSTEROSCOPY IN AUB}

\section{Ambulatory hysteroscopy and diagnosis}

AUB affects women of all ages and includes heavy menstrual bleeding (HMB), unscheduled or 'intermenstrual' bleeding (IMB) and postmenopausal bleeding (PMB). Evaluation of the uterine cavity in women with AUB is the commonest indication for hysteroscopy. The conditions for which it can be useful in diagnosis are shown in Table 3. This table follows the classification system for causes of AUB using the acronym 'PALM-COEIN', as recently accepted by the International Federation of Gynecology and Obstetrics (FIGO). ${ }^{13}$

\section{Heavy menstrual bleeding}

$\mathrm{HMB}$ affects one in five women and leads to $21 \%$ of gynaecological referrals from general practitioners. ${ }^{14} 15$ Investigation of HMB is important to exclude serious genital tract disease and to optimise patient outcomes by identifying any underlying pathologies (Table 3) and instituting the most effective and appropriate therapies for such underlying conditions.
A recent economic analysis modelling a variety of diagnostic tests and combination testing strategies found that $\mathrm{OPH}$ or $\mathrm{OPH}$ combined with endometrial biopsy (EB) were the most cost-effective options when the all strategies were compared to a strategy of 'no investigation', where women were simply treated with a levonorgestrel intrauterine system (LNG-IUS). Investigation of HMB based on OPH in a 'one-stop' 'see and treat' setting was also identified as the most cost-effective option for women with HMB wanting to retain their fertility and in women who were refractory to LNG-IUS treatment in primary care. ${ }^{16}$ Inevitably, such decision analyses cannot account for all the nuances of testing. For example, this model did not take account of the ability of transvaginal ultrasound scanning (TVS) to image the adnexa and wider pelvis. However, OPH does appear to have an integral role in the diagnostic work-up of HMB.

\section{Intermenstrual bleeding}

IMB is usually of benign origin and is commonly associated with exogenous contraceptive hormones or attributed to physiological causes. It is important to exclude cervical abnormalities such as polyps, cervicitis or neoplasia as well as excluding lower genital tract infection. The place of hysteroscopy in the routine diagnostic approach to IMB is unclear. If symptoms persist or if the IMB is heavy, especially in women aged over 45 years, then further endometrial evaluation is appropriate to diagnose the endometrial pathologies described in Table 3.

\section{Postmenopausal bleeding}

PMB is an important problem because it can be the first symptom of endometrial cancer and therefore 
Box 1 Key recommendations for best practice in outpatient hysteroscopy (adapted from Clark et al. ${ }^{5}$ )

1 All gynaecology units should provide a dedicated outpatient hysteroscopy service that is appropriately sized, equipped and staffed, and located outside the formal operating theatre setting. The health care professional(s) should have the necessary skills and expertise to carry out diagnostic and/or therapeutic outpatient hysteroscopy.

2 Written patient information should be provided before the appointment and consent for the procedure should be taken.

3 Women without contraindications should be advised to consider taking standard doses of non-steroidal anti-inflammatory drugs 1 hour before their appointment, but routine use of opiate analgesia should be avoided.

4 Routine cervical preparation before outpatient hysteroscopy should not be used unless dilatation beyond Hegar 6 is anticipated

5 Miniature hysteroscopic systems ( $\leq 4 \mathrm{~mm}$ outer diameter) should be used for diagnostic outpatient hysteroscopy. Choice of hysteroscope (e.g. flexible or rigid; $0^{\circ}$ or fore-oblique distal lenses) should be left to the discretion of the operator.

6 Carbon dioxide or normal saline can be used as distension media for diagnostic outpatient hysteroscopy, but saline should be used for operative procedures.

7 Routine, blind cervical dilatation should be avoided.

8 Topical application of local anaesthetic to the ectocervix should be considered where a cervical tenaculum is necessary. Routine administration of intracervical or paracervical local anaesthetic should be used where larger diameter hysteroscopes are being employed (outer diameter $>5 \mathrm{~mm}$ ) and where the need for cervical dilatation is anticipated (e.g. cervical stenosis). Standard protocols regarding the type, maximum dosage and route of administration of anaesthesia should be implemented.

9 Conscious sedation should not be routinely used in outpatient hysteroscopic procedures.

10 Vaginoscopy (avoiding the use of a vaginal speculum or cervical instrumentation) should be the standard technique for outpatient hysteroscopy.

requires urgent referral for investigation and diagnosis. However, it is important to remember that the majority of women presenting with PMB will have a benign cause, with only a small number having premalignant hyperplastic or malignant disease. ${ }^{17} 18$ In contrast to the investigation of $\mathrm{HMB}$ and IMB, the initial diagnostic work up for PMB is standardised, with published guidelines directing best practice to detect or exclude endometrial cancer. Initial TVS measurement of endometrial thickness is generally recommended and has been shown to be the most cost-effective strategy. ${ }^{17}$ 19-21 If TVS is abnormal ('screen-positive'), further investigation, including hysteroscopy in most cases, is necessary to establish the pathology and to guide appropriate treatment.

\section{Ambulatory hysteroscopy and treatment}

Many of the pathologies diagnosed by ambulatory hysteroscopy are suitable for immediate treatment as part of the same hysteroscopic procedure ('see and treat'). The categories of AUB are taken from those listed in Table 3.

AUB-endometrium (AUB-E)

The recommended first-line treatment for $\mathrm{HMB}$ in women not actively trying to conceive is insertion of an LNG-IUS. ${ }^{15}$ OPH can be useful at the time of fitting the LNG-IUS in women where insertion is anticipated to be difficult, for example, narrow cervix (some nulliparous women, previous deliveries by caesarean section, past cervical cone biopsy), adverse uterine anatomy (acute flexion/retroversion, presence of fibroids) or patient factors limiting access to the lower genital tract such as obesity, anxiety or limited mobility. In cases that have not responded to LNG-IUS treatment, OPH can provide valuable information regarding suboptimal placement of a device or the presence of focal pathologies, endometrial disease or cavity enlargement.

Endometrial ablation should be offered to women with AUB-E who are certain that they will not wish to conceive in the future and where the LNG-IUS is either not desired, ineffective, not tolerated or contraindicated. ${ }^{15}$ 'Second-generation' ablation techniques are technically easier and quicker to perform than the hysteroscopic (first-generation) ablative techniques, and are safer and more cost effective. Reviews have found no evidence of any difference between the two in terms of improvement in HMB or patient satisfaction. $^{22} 23$ The short duration, miniaturisation and semi-automation of some second-generation techniques lends them to being performed in an outpatient setting. Trials have demonstrated comparable effectiveness of ambulatory treatment using local anaesthesia and traditional approaches under general anaesthesia, and good levels of acceptability. ${ }^{24-26}$

The two most commonly used second-generation ablation modalities in the outpatient setting are thermal balloon ablation (TBA) 27 and radiofrequency impedance controlled ablation (RFA) procedures. $^{29}$ In the ambulatory setting, RFA was significantly quicker than TBA, which is advantageous as complete uterine anaesthesia may be impossible to achieve. ${ }^{25}$ In all cases, following any dilatation of the cervix that may be required for introduction of the ablation instrument, hysteroscopy should be performed to assess the uterine cavity, to ensure that 
Table 3 Potential causes of abnormal uterine bleeding described using the PALM-COEIN classification system ${ }^{13}$

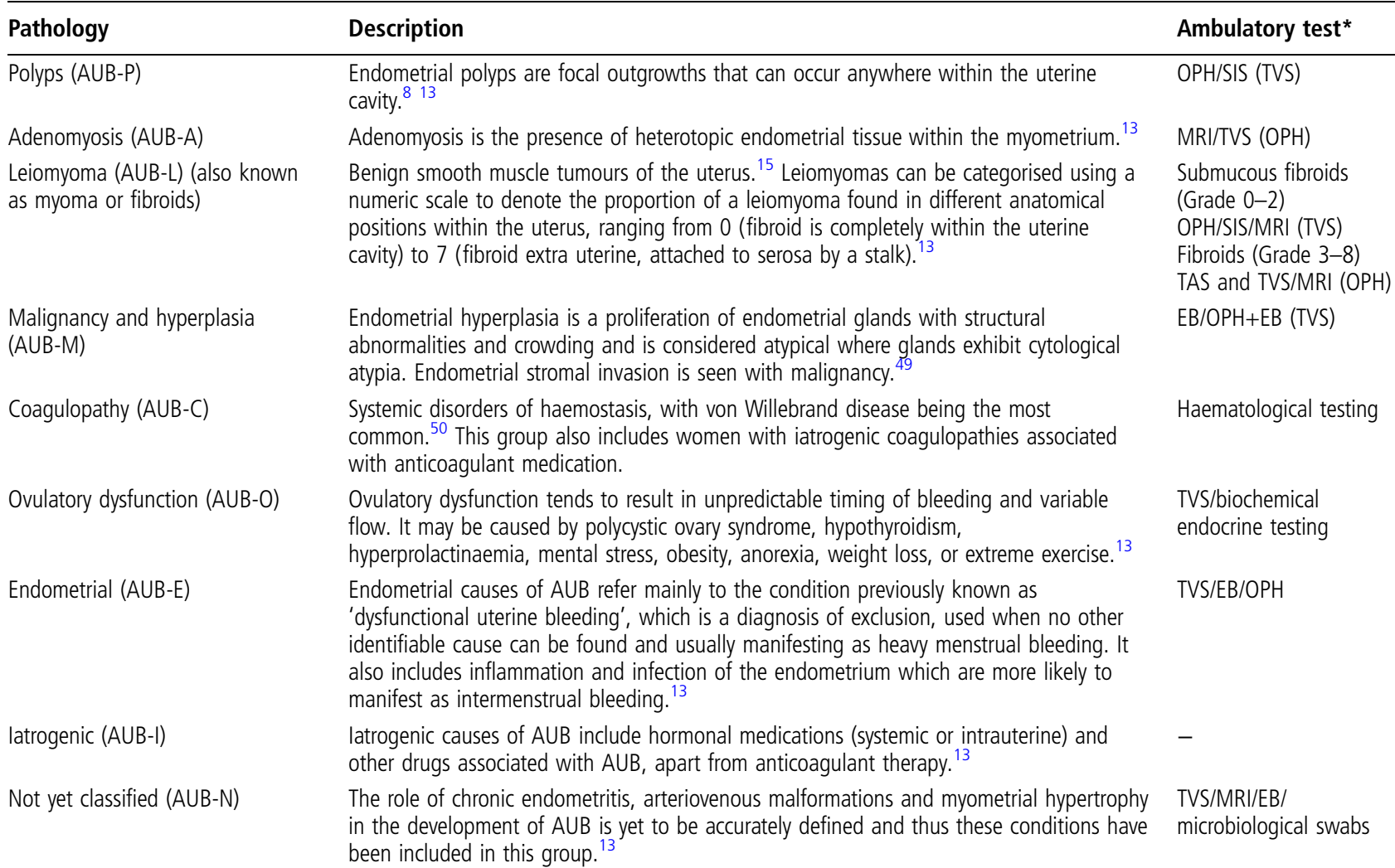

*Ambulatory tests shown in parentheses are those that can be used to aid diagnosis of particular pathologies but are considered second best. $A \cup B$, abnormal uterine bleeding; DB, hysteroscopically-directed biopsy; EB, endometrial biopsy; MRI, magnetic resonance imaging; OPH, outpatient hysteroscopy; SIS, saline infusion sonography; TAS, transabdominal ultrasound scan; TVS, transvaginal ultrasound scan.

there are no contraindications such as suspected endometrial disease or congenital or acquired anomalies causing significant cavity distortion. Furthermore, it is important to determine that there has been no unrecognised false passage or perforation following cervical dilatation. ${ }^{30}$ Current protocols utilise simple preoperative analgesia and local anaesthetic cervical blocks. More recently, local anaesthesia injected hysteroscopically into the uterine fundus has been used to try to reduce peri-operative pain. ${ }^{31}$

Some practitioners advocate concomitant placement of the LNG-IUS. ${ }^{32}{ }^{33}$ The LNG-IUS can provide effective contraception, may enhance treatment efficacy post-ablation and can protect against endometrial hyperplasia in those women deemed to have risk factors. However, the increased cost, and risks of infection, rare systemic hormonal side effects or device embedment, mean that this should only be considered in specific circumstances and after thorough discussion and documentation of this 'off-label' usage, or within a research context. In women requiring contraception after endometrial ablation, all methods should be discussed including the use of concomitant ambulatory hysteroscopic sterilisation. Some data are available to support this approach ${ }^{34-36}$ but more information is required to evaluate its contraceptive efficacy and short-term infective morbidity.
AUB-polyps (AUB-P)

The feasibility of outpatient hysteroscopic polypectomy has been demonstrated using a variety of mechanical and electrosurgical instruments. ${ }^{37} 38$ Fine scissors and grasping forceps for use with continuous flow hysteroscopes have been largely superseded by bipolar electrodes, which provide rapid cutting, slicing through polyps or fibroids efficiently, although additional instruments such as grasping forceps or snares have to be employed to retrieve the material from the uterine cavity. With large glandulocystic polyps, smaller fibrous lesions or cervical stenosis, retrieval with such fine hysteroscopic instruments can be difficult and the surgeon will then have to dilate the cervix after injecting cervical or paracervical local anaesthesia and to try again using the same instruments, or to employ traditional polyp forceps in a blind fashion. This can be associated with pain if the polyp is not located easily, and blind instrumentation of the uterine cavity should be avoided where possible because of the risk of trauma. A large randomised controlled trial (RCT) comparing the effectiveness of ambulatory and day-case uterine polypectomy found that outpatient polypectomy is 'non-inferior' to the day-case procedure for the treatment of polyp-induced AUB. ${ }^{39}$

In response to the tissue retrieval limitations listed above, hysteroscopic morcellators have been 
developed. These integrate tissue cutting with aspiration, thereby obviating the need for separate tissue retrieval. Hysteroscopic morcellator systems require a specific hysteroscope with an offset eyepiece to allow the morcellator to be passed through the operating channel. Morcellators are available in a variety of sizes, with the smaller ones (hysteroscope diameter $<6.5 \mathrm{~mm}$ ) being more suitable for use in the outpatient setting. The feasibility and simplicity of the technique has been demonstrated and a RCT comparing the speed, pain, acceptability and feasibility of hysteroscopic morcellation against bipolar electrosurgery has shown that polyp removal is quicker, less painful and more likely to be complete with the morcellator. ${ }^{40} 41$

\section{AUB-leiomyoma (AUB-L)}

Submucous fibroids can be removed or ablated in the outpatient setting ${ }^{42}$ using bipolar electrosurgery, although this is only generally feasible with smaller Grade 0 (see Table 3 for grading) non-fundal lesions. The smallest diameter hysteroscopic morcellators most suited for use in a conscious outpatient will not cut through fibrous tissue, although slightly larger ones will. Traditional, larger diameter resectoscopes are advocated by some practitioners in an outpatient setting, ${ }^{43}$ but in general, given the vascularity of larger submucous (Grade 1) fibroids, the conventional operating theatre setting with general or regional anaesthesia is more appropriate. OPH is useful to diagnose submucous fibroids but also to allow the surgeon to plan how best to remove them surgically, for example, outpatient versus inpatient; needle electrode en bloc excision versus resection in chips versus morcellation; down-regulation with gonadotrophinreleasing hormone analogues or ulipristal acetate. There is currently some interest in incising the capsule of a detected Grade 1 or 2 submucous lesion at outpatient diagnosis, thereby 'preparing' the fibroid for later resection under anaesthesia, the hope being that a Grade 1 fibroid will be extruded into the uterine cavity by myometrial contraction, in effect turning it into an easier-to-resect Grade 0 fibroid. No data to support this approach are available, so it cannot be recommended at present.

AUB-malignancy and hyperplasia (AUB-M)

Ambulatory hysteroscopy can diagnose global or focal endometrial hyperplasia or malignancy ${ }^{44} 45$ and aid blind or directed EB. Directed biopsy can be achieved using hysteroscopic graspers or the newer morcellators. For blind biopsy of larger areas of the endometrial cavity, the $\mathrm{H}$ Pipelle ${ }^{\circledR}$ may be used. This is a $3.1 \mathrm{~mm}$ diameter suction biopsy cannula based on the well-established Pipelle that can be inserted through the inner sheath of a suitable hysteroscope once the telescope has been removed. This avoids the need to traverse the cervical canal blindly after hysteroscopy, which can be a problem in a minority of cases. ${ }^{46}$
Endometrial hyperplasia is often found within polyps, so complete hysteroscopic removal of polyps is recommended for diagnosis and treatment, followed by progestogenic therapy and $\mathrm{OPH}$ endometrial surveillance as appropriate. ${ }^{8}$

\section{CONCLUSIONS}

Hysteroscopy has evolved from a reluctant diagnostic adjunct to the traditional diagnostic 'D\&C', in hospital and under general anaesthesia, to a predominantly ambulatory procedure providing both diagnosis and treatment. This change has resulted from the development of pioneering technologies, patient demand, the drive of enthusiastic clinicians and the need to conserve scarce health care resources whilst improving clinical care. $\mathrm{OPH}$ is a key component of diagnosis in all types of AUB, allowing optimal treatment strategies to be employed, based on the underlying uterine pathology. AUB of endometrial origin (AUB-E), uterine polyps and small submucous fibroids can be treated at the time of hysteroscopic diagnosis, providing convenience to women, more rapid resolution of symptoms and enhanced efficiency of care. Outpatient 'see and treat' approaches are likely to be further promoted in the UK through more favourable reimbursement, replacing financial incentives that support outdated inpatient treatments. Reports from recent research are clarifying the role of OPH in the diagnosis and treatment of AUB. Advances in instrumentation such as the use of integrated, portable, battery-operated imaging (e.g. the Endosee ${ }^{\circledR}$ device) and improvements in pain management will enable ambulatory hysteroscopy for AUB to move increasingly into the community setting.

Twitter Follow Natalie Cooper at @docnamc and Justin Clark at @TJustinC

Competing interests $\mathrm{T}$ Justin Clark was a Consultant to Conceptus. He received honoraria from Hologic and Ethicon for clinician training which were paid into a charitable account to fund research. He has also received honoraria for lecturing from Nordic Pharma. He has received trial funding from

Hologic and is currently a member of their European Advisory Board. He has received funding for travel and accommodation at national and international conferences from Ethicon, Hologic, Conceptus and Smith \& Nephew. He has received research grants from Cytyc (now Hologic) and Smith \& Nephew.

Provenance and peer review Commissioned; externally peer reviewed.

\section{REFERENCES}

1 Robinson LLL, Cooper NAM, Clark TJ. The role of ambulatory hysteroscopy in reproduction. J Fam Plann Reprod Health Care 2013;39:127-135.

2 Heit JA, Silverstein MD, Mohr DN, et al. Risk factors for deep vein thrombosis and pulmonary embolism: a population-based case-control study. Arch Intern Med 2000;160:809-815.

3 Graffunder EM, Venezia RA. Risk factors associated with nosocomial methicillin-resistant Staphylococcus aureus (MRSA) infection including previous use of antimicrobials. J Antimicrob Chemother 2002;49:999-1005. 
4 Plowman R, Graves N, Griffin MA, et al. The rate and cost of hospital-acquired infections occurring in patients admitted to selected specialties of a district general hospital in England and the national burden imposed. J Hosp Infect 2001;47:198-209.

5 Clark TJ, Cooper NAM, Kremer C. Best Practice in Outpatient Hysteroscopy. RCOG/BSGE, 2011. https://www.rcog.org.uk/ globalassets/documents/guidelines/gtg59hysteroscopy.pdf [accessed 28 August 2015].

6 Cooper NAM, Khan KS, Clark TJ. Local anaesthesia for pain control during outpatient hysteroscopy: systematic review and meta-analysis. BMJ 2010;340:c1130.

7 Bettocchi S, Selvaggi L. A vaginoscopic approach to reduce the pain of office hysteroscopy. J Am Assoc Gynecol Laparosc 1997;4:255-258.

8 Clark TJ, Gupta JK. Handbook of Outpatient Hysteroscopy. A Complete Guide to Diagnosis and Therapy (1st edn). London, UK: Hodder Education, 2005.

9 Kumar V, Gupta JK. Hysteroscopic local anaesthetic intrauterine cornual 'focal local' block before endometrial ablation with direct cervical block in an outpatient setting: a feasibility study. Eur J Obstet Gynecol Reprod Biol 2013;170:222-224.

10 Clark TJ. Vaginoscopy Against Standard Treatment (VAST): a randomised controlled trial. 2015. clinicaltrials.gov. https:/ clinicaltrials.gov/ct2/show/NCT01972945 [accessed 2 July 2015].

11 Janse JA, Goedegebuure R, Veersema S, et al. Hysteroscopic sterilization using a virtual reality simulator: assessment of learning curve. J Minim Invasive Gynecol 2013;20:775-782.

12 Haerizadeh H, Frappell J. The role of simulation in surgical skills training in gynaecological endoscopy. Best Pract Res Clin Obstet Gynaecol 2013;27:339-347.

13 Munro MG, Critchley HO, Broder MS, et al. FIGO Working Group on Menstrual Disorder. FIGO classification system (PALM-COEIN) for causes of abnormal uterine bleeding in nongravid women of reproductive age. Int J Gynaecol Obstet 2011;113:3-13.

14 Justin W, Ibraheim M, Bagtharia S, et al. Current minimal access techniques in the treatment of heavy menstrual bleeding. Obstet Gynaecol2007;9:224-232.

15 National Institute for Clinical Excellence. Heavy Menstrual Bleeding (NICE Guideline CG44). 2007. http://www.nice.org. uk/Guidance/CG44 [accessed 2 July 2015].

16 Cooper NAM, Barton PM, Breijer MC, et al. Cost-effectiveness of diagnostic strategies for the management of abnormal uterine bleeding (heavy menstrual bleeding and post-menopausal bleeding): a decision analysis. Health Technol Assess 2014;18:1-201.

17 Scottish Intercollegiate Guidelines Network. Investigation of Post-Menopausal Bleeding - A National Clinical Guideline. Edinburgh, UK: Royal College of Physicians, 2002.

18 Burbos N, Musonda P, Giarenis I, et al. Age-related differential diagnosis of vaginal bleeding in postmenopausal women: a series of 3047 symptomatic postmenopausal women. Menopause Int 2010;16:5-8.

19 Clark TJ, Barton PM, Coomarasamy A, et al. Investigating postmenopausal bleeding for endometrial cancer: cost-effectiveness of initial diagnostic strategies. BJOG 2006;113:502-510.

20 Gupta JK, Chien PFW, Voit D, et al. Ultrasonographic endometrial thickness for diagnosing endometrial pathology in women with postmenopausal bleeding: a meta-analysis. Acta Obstet Gynecol Scand 2002;81:799-816.
21 Timmermans A, Opmeer BC, Khan KS, et al. Endometrial thickness measurement for detecting endometrial cancer in women with postmenopausal bleeding: a systematic review and meta-analysis. Obstet Gynecol 2010;116: 160-167.

22 Lethaby A, Hickey M, Garry R, et al. Endometrial resection/ ablation techniques for heavy menstrual bleeding. Cochrane Database Syst Rev 2009;4:CD001501.

23 Middleton LJ, Champaneria R, Daniels JP, et al. Hysterectomy, endometrial destruction, and levonorgestrel releasing intrauterine system (Mirena) for heavy menstrual bleeding: systematic review and meta-analysis of data from individual patients. BMJ 2010;341:c3929.

24 Wallage S, Cooper KG, Graham W, et al. A randomised trial comparing local versus general anaesthesia for microwave endometrial ablation. BJOG 2003;110:799-807.

25 Clark TJ, Samuel N, Malick S, et al. Bipolar radiofrequency compared with thermal balloon endometrial ablation in the office: a randomized controlled trial. Obstet Gynecol 2011;117:109-118.

26 Glasser MH, Heinlein PK, Hung YY. Office endometrial ablation with local anesthesia using the HydroThermAblator system: comparison of outcomes in patients with submucous myomas with those with normal cavities in 246 cases performed over 5(1/2) years. J Minim Invasive Gynecol 2009;16:700-707.

27 Varma R, Soneja H, Samuel N, et al. Outpatient thermachoice endometrial balloon ablation: long-term, prognostic and quality-of-life measures. Gynecol Obstet Invest 2010;70:145-148.

28 Clark TJ, Gupta JK. Outpatient thermal balloon ablation of the endometrium. Fertil Steril 2004;82:1395-1401.

29 Samuel NC, Karragianniadou E, Clark TJ. Outpatient versus day-case endometrial ablation using the NovaSure impedance-controlled ablative system. Gynecol Surg 2009;6:3-9.

30 Medicines and Healthcare products Regulatory Agency (MHRA). Medical Device Alert. Devices used for endometrial ablation. All makes and models. https://assets.digital. cabinet-office.gov.uk/media/5485ac4040f0b60241000293/ con068378.pdf [accessed 2 July 2015].

31 Skensved H. Global local anaesthesia: combining paracervical block with intramyometrial prilocaine in the fundus significantly reduces patients' perception of pain during radio-frequency endometrial ablation (Novasure) in an office setting. Gynecol Surg 2012;9:207-212.

32 Vilos AG, Vilos GA, Doulaverakis C, et al. Clinical outcomes of thermal balloon endometrial ablation (Thermablate EAS) with and without concomitant use of levonorgestrel intra-uterine system (LNG-IUS) in women with abnormal uterine bleeding: a pilot study. J Minim Invasive Gynecol 2013;20(6 Suppl.):S78-S79.

33 Sohn B, Vilos GA, Vilos AG, et al. Resectoscopic rollerball endometrial ablation and concomitant levonorgestrel-releasing intrauterine system in women with abnormal uterine bleeding: is the combination better? J Minim Invasive Gynecol 2013;20: S22-S23.

34 Mircea CN, Goojha C, Thiel JA. Concomitant NovaSure endometrial ablation and Essure tubal sterilization: a review of 100 cases. J Obstet Gynaecol Can 2011;33:361-366.

35 Donnadieu AC, Deffieux X, Gervaise A, et al. Essure sterilization associated with endometrial ablation. Int J Gynaecol Obstet 2007;97:139-142. 
36 Valle RF, Valdez J, Wright TC, et al. Concomitant Essure tubal sterilization and Thermachoice endometrial ablation: feasibility and safety. Fertil Steril 2006;86:152-158.

37 Cicinelli E, Tinelli R, Loiudice L, et al. Office polypectomy without anesthesia with Alphascope: a randomized controlled study. J Minim Invasive Gynecol 2011;18:796-799.

38 Garuti G, Centinaio G, Luerti M. Outpatient hysteroscopic polypectomy in postmenopausal women: a comparison between mechanical and electrosurgical resection. J Minim Invasive Gynecol 2008;15:595-600.

39 Cooper NAM, Clark TJ, Middleton LJ, et al. A randomised trial of outpatient versus inpatient uterine polyp treatment for abnormal uterine bleeding. BMJ 2015;350:h1398.

40 Smith PP, Middleton LJ, Connor ME, et al. Hysteroscopic morcellation compared with electrical resection of endometrial polyps. Obstet Gynecol 2014;123:745-751.

41 Rovira PJ, Degollada BM, Mancebo MG, et al. A comparison of hysteroscopic mechanical tissue removal with bipolar electrical resection for the management of endometrial polyps in an ambulatory care setting: preliminary results. J Minim Invasive Gynecol 2015;22:439-445.

42 Clark TJ, Mahajan D, Sunder P, et al. Hysteroscopic treatment of symptomatic submucous fibroids using a bipolar intrauterine system: a feasibility study. Eur J Obstet Gynecol Reprod Biol 2002;100:237-242.

43 Penketh RJA, Griffiths AN, Bruen EM, et al. The Cardiff Shine Project. Outpatient operative hysteroscopy (resection of fibroids and polyps) using conventional monopolar resectoscopes with glycine under local anaesthetic: excellent clinical success and patient satisfaction rates with major financial savings. J Minim Invasive Gynecol 2011;18(6 Suppl.): S81-S82.

44 Lasmar RB, Barrozo PRM, de Oliveira MAP, et al. Validation of hysteroscopic view in cases of endometrial hyperplasia and cancer in patients with abnormal uterine bleeding. J Minim Invasive Gynecol 2006;13:409-412.

45 Clark TJ, Voit D, Gupta JK, et al. Accuracy of hysteroscopy in the diagnosis of endometrial cancer and hyperplasia: a systematic quantitative review. JAMA 2002;288:1610-1621.

46 Madari S, Al-Shabibi N, Papalampros P, et al. A randomised trial comparing the H Pipelle with the standard Pipelle for endometrial sampling at 'no-touch' (vaginoscopic) hysteroscopy. BJOG 2009;116:32-37.

47 Department of Health. Equity and Excellence: Liberating the NHS. https://www.gov.uk/government/publications/ equity-and-excellence-liberating-the-nhs-executive-summary [accessed 2 July 2015].

48 Royal College of Obstetricians and Gynaecologists. High Quality Women's Healthcare: A Proposal for Change. 2011. http://www.rcog.org.uk/globalassets/documents/guidelines/ highqualitywomenshealthcareproposalforchange.pdf [accessed 2 July 2015].

49 Kurman RJ, Kaminski PF, Norris HJ. The behavior of endometrial hyperplasia. A long-term study of 'untreated' hyperplasia in 170 patients. Cancer 1985;56:403-412.

50 Shankar M, Lee CA, Sabin CA, et al. von Willebrand disease in women with menorrhagia: a systematic review. BJOG 2004;111:734-740.

\section{JOURNAL REVIEW WRITERS}

The Journal regularly reviews articles from related publications and is looking to recruit more volunteers to compile these short reviews. For further information and/or to offer your services (at most once or twice a year) please e-mail your contact details to the Journal Editorial Office together with a note of any special interests and/or expertise to assist us in allocating relevant articles to individual reviewers. For further information on this role please contact the Journal Editorial Office at journal@fsrh.org. 